\title{
МЫ ОТЛИЧАЕМСЯ \\ от других спутниковых операторов
}

Рассказывает генеральный директор АО "Газпром космические системы" Д.Н.Севастьянов

DOI: $10.22184 / 2070-8963.2019 .82 .5 .28 .31$

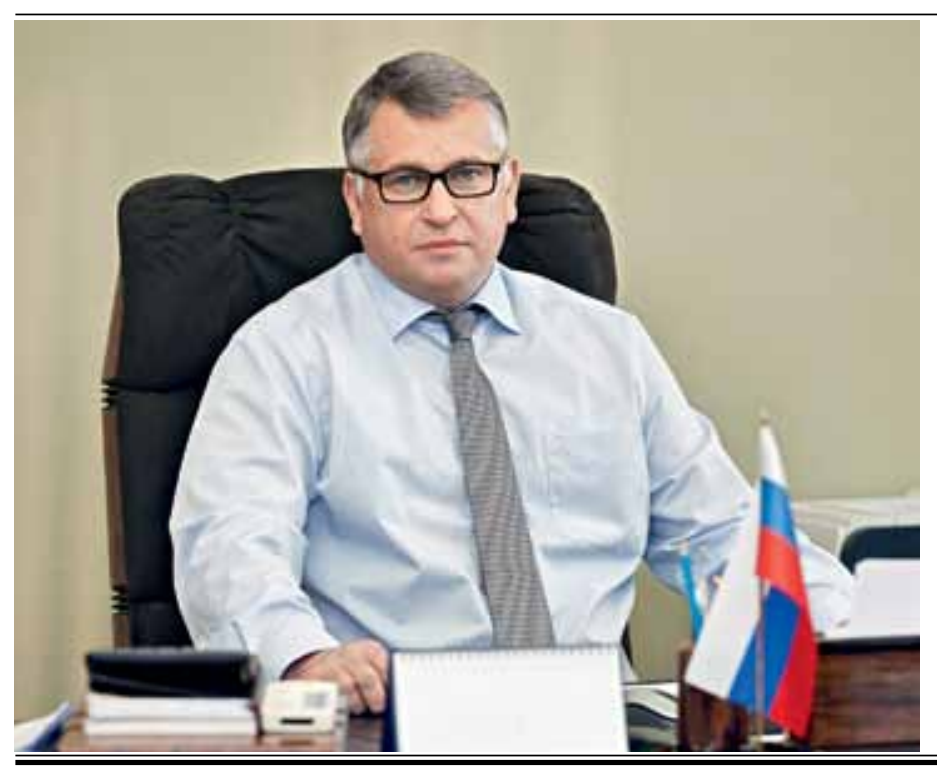

Дмитрий Николаевич, спутник "Ямал-601", запущенный с Байконура 30 мая, уже находится в коммерческой эксплуатации?

В июне "Ямал-601" занял свою рабочую точку на геостационарной орбите - 49 град.в.д. В июле мы полностью приняли на себя управление спутником. Летные испытания успешно завершены, и восьмого августа проведена предварительная приемка спутника, предусмотренная контрактом с производителем. Окончательная приемка произойдет в сентябре после того как "Ямал-601" пройдет несколько так называемых теневых участков орбиты. Есть такие периоды, когда в течение какого-то времени спутник попадает в тень Земли и питается не от солнечных батарей, а исключительно от аккумуляторов. И по существующей практике оператор окончательно принимает спутник после того, как тот побывает в такой ситуации. Все сети С-диапазона, работавшие на спутнике "Ямал-202", буквально за два дня были переведены на новый спутник. Эта операция прошла быстро и без проблем, поскольку зона покры тия и частотный план "Ямала-601" те же, что и у предшественника. Тем самым "Ямал-601" с первого же дня своей коммерческой эксплуатации начал зарабатывать, что всегда благоприятно сказывается на экономике проекта.
Что станет с "Ямалом-202"?

Несмотря на то, что "Ямал-202" на орбите без малого 16 лет, мы рассчитываем, что он еще немного поработает. Сейчас мы подбираем этому спутнику другую позицию на орбите, в которую сможем его переместить и удерживать по долготе. Для удержания по широте топлива уже недостаточно, и наклонение его орбиты начнет увеличиваться, но на рынке суще ствует спрос на емкость и таких спутников. Особенно это касается мобильных приложений (например, связь и доступ в интернет на морских судах), для которых нестабильное положение спутника в точке не критично, ведь абонент ские станции на таких объектах 
имеют следящие антенны. И мы видим потенциальный интерес к этому спутнику у ряда компаний, оказывающих услуги для судов в Тихом океане.

На "Ямале-601" установлена также полезная нагрузка Ка-диапазона, которая предназначена преимущественно для оказания массовых услуг ШПД. Для ГКС это новый бизнес. Как будет формироваться клиентская база?

Бизнесом спутникового широкополосного доступа мы занимаемся уже несколько лет, но в Кu-диапазоне. Он организован на спутниках "Ямал-401", "Ямал-402", "Ямал-300К". Мы имеем мультисервисные платформы раз личных производителей, но для работы с населением и малым бизнесом используем в основном платформу от компании Newtec. Два хаба Newtec версии Sat3Play находятся в подмосковном Щелково и еще один хаб Newtec Dialog - в Хабаровске (в самой последней и продвинутой версии). Для работы в Ка-диапазоне была выбрана технология компании Gilat, а хабы были размещены в Переславле-Залесском и в Новосибирской области. Так что этой осенью планируем начать опытно-коммерческую эксплуатацию всей системы в Ка-диапазоне.

Что касается формирования клиентской базы Ка-диапазона, то у нас принцип такой: мы не ставим перед собой невыпол нимую задачу по самостоятельной реализации такой большой пропускной способности (а это около 30 Гбит/с) конечным потребителям. Мы это будем делать совместно с виртуальными операторами (VNO). В этой роли мы видим преимущественно наших старых знакомых провайдеров, которые используют емкость "Ямалов" уже по нескольку лет.
Некоторые из них уже зафиксировали свой интерес к новому бизнесу и готовность к тестированию нашего Ка-диапазона. Мы же позиционируем себя, прежде всего, как владельцы космического сегмента и технологической платформы - и предлагаем на рынке оптом пропускную способность, измеряемую в мегабитах в секунду.

Однако мы все же оставляем за собой роль поставщика услуг индивидуального и коллективного доступа в интернет для клиентов напрямую и делаем это по ряду причин. Во-первых, потому что мы уже работаем в Кu-диапазоне в таком качестве и имеем отлаженную систему продаж на розничном рынке. Во-вторых, мы хотим сами ощущать нюансы рынка конечных клиентов для того, чтобы угадать с рыночным позиционированием наших будущих спутниковых и наземных активов. Затем, мы хотим нести полную ответственность при предоставлении конечных услуг компаниям Группы Газпром. И наконец, дополнительный доход за счет добавленной стоимости нам также будет нелишним. Поэтому мы продолжим продвижение услуг широкополосного доступа под своим именем, будем по-прежнему работать с дилерами и торговыми партнерами, проводить семинары и рекламные компании в интернете и на телевидении. Но все это мы будем делать сбалансированно, с учетом работающих с нами VNO с тем, чтобы исключить поводы для внутренней конкуренции.

\section{Как будут сочетаться похожие} услуги в Ku- и Ка-диапазонах?

Добавляя услуги в Ка-диапазоне, мы расширяем возможности для существующих и будущих клиентов, которые вольны выбрать ту или иную технологию. И критерием для этого во многом будет соотношение "цена - качество". Население, видимо, будет искать более экономичные решения, а вот производственный сектор, скорее всего, будет ставить во главу угла надежность сервиса, ведь того требуют, например, технологические сети. Конечно, если говорить о бизнесе операторов и провайдеров, то всегда есть определенные опасения - не будет ли новая услуга "поедать" старую. Нам все же сейчас кажется, что спрос будет расти на услуги в обоих диапазонах. Если говорить о территориальном факторе, то восток России предпочтет Кu-диапазон, ведь широкие лучи позволяют покрыть 100\% труднодоступных регионов, да и сама технология в Ки-диапазоне более приспособлена для работы в сложных климатических условиях. А вот в центральной части России мы ожидаем преимущество будет иметь Ка-диапазон.

Как вы считаете, может ли "Ямал-601" изменить ситуацию на рынке спутникового ШПД Ка-диапазона? Будут ли понижаться цены на эту услугу?

Сложно отвечать за других операторов. Мы планируем предлагать наш новый продукт по довольно привлекательным ценам. Это касается и продаж абонентских терминалов, и собственно услуг. С увеличением пропускной способности спутника соответственно понижается себестоимость одного мегабита в секунду или одного мегабайта переданной информации. При этом, конечно, предлагая интересные цены, мы рассчитываем на более быстрый прирост клиентской базы.

И клиентская база "Ямала601" в Ка-диапазоне может действительно составить (где-то прочла) порядка 200-300 тыс. подписчиков? 
В принципе, да. Наш бизнесплан и производительность оборудования рассчитаны на то, что на четвертый-пятый год эксплуатации спутника по мере его загрузки мы спокойно переварим такие объемы. Разумеется, это не только наши собственные клиенты, но и клиенты наших VNO-операторов. Количество потребителей не является самоцелью, главной целью все же являются денежные потоки, поэтому мы планируем предлагать услуги в Ка-диапазоне не только домохозяйствам, но и крупному бизнесу. А производительность оборудования будет наращиваться по мере необходимости - в этом плане наши расходы на наземную часть сети ГКС сбалансированы с доходом и объемом клиентской базы.

Еще не начался процесс закупок этих терминалов?

Процесс закупок терминалов запущен. Завершаются испытания хабов в Переславле-Залесском и под Новосибирском, и готовится первая поставка терминалов. Мыдаем нашим партнерам и операторам VNO возможность выбора - покупать напрямую у производителя по той же цене, которую мы зафиксировали в контракте с Gilat, либо у нас, но уже с учетом наших расходов на закупку, транспортировку и хранение. Примерно в сентябре готовность хабов будет подтверждена, и первая партия абонентских терминалов тоже поступит.

\section{Кооперацию с другими опе-} раторами спутниковой связи практикуете?

Сейчас во всем мире настали непростые времена для спутниковой связи. Политическая и экономическая нестабильность в ряде регионов мира, значительные колебания курсов валют, снижение деловой активности потребителей, появление большого количества новых спутников, развитие технологий, альтернативных спутниковым (оптоволоконные линии, наземный беспроводный доступ) - все это вызвало превышение предложения над спросом, усиление конкуренции и снижение цен на рынке космических услуг.

Одним из путей смягчения ситуации спутниковые операторы видят в кооперации друг с другом. Это может быть создание совместных спутников для снижения рисков и капитальных затрат каждого из участников или использование существующих орбитальных активов друг друга для реализации каких-либо проектов. Для нас такая работа не нова. Если обратиться к относительно недавней истории, то можно вспомнить сотрудничество с глобальным оператором SES, с которым мы реализовали два значимых проекта. Сначала в точку 55 град. в. д., когда еще не запустили в нее "Ямал-402", поставили спутник Astra 1F, принадлежащий SES. Тем самым мы защитили эту позицию и наработали клиентскую базу, которую потом перевели на "Ямал-402", обеспечив первоначальную загрузку нового спутника. В рамках второго нашего проекта с SES спутник "Ямал-300K" сейчас работает в точке, которую мы взяли в пользование у этой компании.

Планируется, что проекты ГКС войдут в ФЦП "Сфера". Чем это выгодно для ГКС?

Мы с воодушевлением отнеслись к возможности включить в ФЦП "Сфера" нашу программу развития группировки спутников связи "Ямал", спутников дистанционного зондирования Земли "Смотр" и строительства завода по производству космических аппаратов. Видим в этой ФЦП потенциал для реализации принципов государственно-частного партнерства. При этом мы не просим госбюджетное финансирование для реализации своих проектов. Наш интерес заключается в другом. Эта программа, на наш взгляд, расширит рынки сбыта наших телекоммуникационных и геоинформационных услуг, а также поможет загрузить заказами будущий завод. И кроме того, ориентация этой программы на разработку новейших космических технологий дает нам надежду на то, что в России появятся конкурентоспособные разработки, которые позволят нам как оператору получить качественную и недорогую отечественную космическую технику и успешно вести свой операторский бизнес.

У спутников, которые последуют за "Ямалом-601", тоже будут транспондеры в традиционных и новых диапазонах?

Я думаю, что да. Спрос на емкость ставших уже классическими спутниками связи с широкими зонами обслуживания, работающими в хорошо освоенных частотных диапазонах (С и $\mathrm{Ku}$ ), будет оставаться более или менее стабильным. Они и впредь будут востребованы для ряда спутниковых приложений, в первую очередь для телевидения. Однако, в условиях снижения цен на спутниковую емкость доходность таких спутников падает, и в среднесрочной перспективе бизнес на их основе приблизится к границе рентабельности. У традиционных спутников есть системные ограничения: широкие зоны обслуживания при всей их привлекательности не позволяют многократно использовать имеющийся ограниченный орбитально-частотный ресурс и тем самым значительно увеличивать пропускную способность спутника.

А у космических аппаратов С высокой пропускной 
способностью (High Throughput Satellites, HTS), которые начали появляться на коммерческом рынке несколько лет назад, таких ограничений практически нет. Если классические спутники свой потенциал почти исчерпали, то более высокочастотные диапазоны и многолучевое покрытие космических аппаратов HTS обеспечивают на порядок или два более высокую техническую пропускную способность. Задача оператора - эту увеличенную пропускную способность продать, потому что недогруженные спутники тоже не окупятся. Поэтому при восполнении и развитии системы "Ямал" ГКС планирует запускать как спутники с высокой пропускной способностью, так и комбинированные спутники, сочетающие сильные стороны традиционных космических аппаратов и спутников HTS.

При этом мы отличаемся от других спутниковых операторов, поскольку осваиваем соседние ниши на рынке. Например, мы хотим развивать бизнес Д33 - второй по объемам и по доходности в мире после спутниковой связи. Ну и еще одно наше отличие - мы планируем построить завод.

В какой стадии реализации находится строительство завода ГКС по производству спутников?

Мы хотим создать в России мощности по производству конкурентоспособных отечественных космических аппаратов с использованием передовых европейских технологий. У нас, как у оператора, есть собственная потребность в недорогих и качественных спутниках. Мы также видим в этом потребность других действующих лиц на рынке космических услуг.

Сейчас завершено проектирование, получено положительное заключение государственной экспертизы. Готовимся к началу строительства. Согласно графику, мы должны получить готовый завод в 2022 году. Следующие наши спутники связи "Ямал" и новые спутники Д33 "Смотр" буду собраны и испытаны уже на новом производстве. Уверены, что такое современное предприятие не обойдут вниманием и сторонние заказчики. и систем (например, в рамках той же программы "Сфера") все больше вовлекать в процесс создания спутников российскую кооперацию.

Недавно прошло Общее собрание акционеров ГКС по итогам прошлого года. Что самое важное можно сказать о том, что произошло в компании и происходит в отрасли?

\section{Согласно графнку, мы должНЫ получить готовый завод в 2022 году}

Создание завода на условиях"под ключ" ведется итальянской компанией Rizzani de Eccher в кооперации с Thales Alenia Space - нашим давним партнером и производителем некоторых спутников "Ямал" и полезных нагрузок. На заводе будет осуществляться интеграция и полный цикл испытаний космических аппаратов связи и Д33 большой и средней размерности. Предусматривается также возможность серийной сборки большого количества перспективных малых КА (преимущественно в рамках ФЦП "Сфера"). Если учесть, что на интеграцию и испытания приходится $15-20 \%$ стоимости спутника, то выполняя эти работы самостоятельно и экономно, мы будем иметь возможность сделать спутники и для себя, и для внешних заказчиков несколько дешевле, чем в среднем на рынке.

Составные части собираемых спутников будут закупаться на конкурентной основе на международном рынке. Мы ставим перед собой задачу постепенно, по мере появления конкурентоспособных по цене и качеству российских разработок бортовых приборов
Главный итог - это то, что ГКС, несмотря ни на какие рыночные тенденции, показал рост выручки почти на 7\%. А если говорить об отрасли в целом, то мы обратили внимание, что в последнее время на уровне органов государственного управления спутниковую связь стали рассматривать как некий катализатор для развития высокотехнологичных отраслей экономики, а сообщество профессионалов все активнее стремится донести властям с различных трибун, что спутниковая связь действительно имеет свои существенные плюсы, что цифровая экономика без нее развиваться не может. Конечно, здесь есть еще много противоречий, в том числе в контексте развертывания сетей 5G, но мы рассчитываем, что спутниковые телекоммуникации не будут недооценены в нашем государстве, потому что только с помощью оптики и наземных беспроводных систем все задачи не решить.

Спасибо за интересный рассказ.

С Д.Н.Севастьяновым беседовала Л.В.Павлова 